Journal for ImmunoTherapy of Cancer

\section{Anti-GD2 IgA kills tumors by neutrophils without antibody-associated pain in the preclinical treatment of high- risk neuroblastoma}

To cite: Evers M, Stip M, Keller K, et al. Anti-GD2 IgA kills tumors by neutrophils without antibody-associated pain in the preclinical treatment of highrisk neuroblastoma. Journal for ImmunoTherapy of Cancer 2021;9:e003163. doi:10.1136/ jitc-2021-003163

- Additional supplemental material is published online only. To view, please visit the journal online (http://dx.doi.org/10. 1136/jitc-2021-003163).

MS, KK and HW contributed equally.

NE and JL contributed equally.

Accepted 17 September 2021

Check for updates

(C) Author(s) (or their employer(s)) 2021. Re-use permitted under CC BY-NC. No commercial re-use. See rights and permissions. Published by BMJ.

For numbered affiliations see end of article.

Correspondence to

Dr Jeanette Leusen;

j.h.w.leusen@umcutrecht.nl

\section{ABSTRACT}

Background The addition of monoclonal antibody therapy against GD2 to the treatment of high-risk neuroblastoma led to improved responses in patients. Nevertheless, administration of GD2 antibodies against neuroblastoma is associated with therapy-limiting neuropathic pain. This severe pain is evoked at least partially through complement activation on GD2-expressing sensory neurons.

Methods To reduce pain while maintaining antitumor activity, we have reformatted the approved GD2 antibody ch14.18 into the IgA1 isotype. This novel reformatted IgA is unable to activate the complement system but efficiently activates leukocytes through the FcoRI (CD89).

Results IgA GD2 did not activate the complement system in vitro nor induced pain in mice. Importantly, neutrophilmediated killing of neuroblastoma cells is enhanced with $\lg A$ in comparison to $\lg \mathrm{G}$, resulting in efficient tumoricidal capacity of the antibody in vitro and in vivo.

Conclusions Our results indicate that employing $\lg \mathrm{A}$ GD2 as a novel isotype has two major benefits: it halts antibody-induced excruciating pain and improves neutrophil-mediated lysis of neuroblastoma. Thus, we postulate that patients with high-risk neuroblastoma would strongly benefit from IgA GD2 therapy.

\section{BACKGROUND}

Neuroblastoma is a pediatric tumor derived from the neural crest, and accounts for $15 \%$ of pediatric cancer mortality. Approximately half of the diagnosed cases of neuroblastoma are classified as high-risk, with a 5-year survival rate of less than $40 \%$ when treated with surgery, chemotherapy and radiotherapy. ${ }^{1} \mathrm{~A}$ major improvement in patient survival came in 2015, with the Food and Drug Administration approval of ch14.18, a chimeric antibody of the IgG1 isotype directed against the ganglioside GD2, expressed on neuroblastoma cells, but also on peripheral and central nervous tissue. Ch14.18 is applied as second-line treatment in combination with interleukin (IL)-2,
Granulocyte-macrophage colony-stimulating factor(GM-CSF) and 11-cis retinoic acid for the treatment of high-risk neuroblastoma after hematopoietic stem cell transplantation. In a large phase III clinical trial, ch14.18 combination therapy resulted in $20 \%$ more event-free survival (EFS) than standard therapy, 2 years after treatment. ${ }^{2}$ Although the inclusion of immunotherapy improved the survival of patients with neuroblastoma, excruciating pain is a major dose-limiting side effect caused by the administration of ch14.18 affecting therapy success. ${ }^{2}$ This severe pain is difficult to manage, and all children who undergo treatment with dinutuximab require the use of significant dosing of morphine (10 $\mu \mathrm{g} / \mathrm{kg} / \mathrm{hour}$ at minimum), and sometimes pretreatment with gabapentin and treatment with lidocaine or ketamine. ${ }^{34}$ Patients would therefore strongly benefit from GD2 treatment that does not induce severe pain.

Ch14.18 has two modes of action. First, antibody-opsonized tumor cells are killed by leukocytes through antibody-dependent cellmediated cytotoxicity (ADCC) that depends on antibody binding to Fc receptors on leukocytes. For IgG1-mediated antibody therapy, natural killer (NK) cells are regarded as the most important effector cell type. However, for IgG-mediated ADCG against neuroblastoma, there is evidence that granulocytes play an important role, because granulocyte activation positively correlates with therapeutic outcome when treated with an antibody directed against GD2. ${ }^{5-7}$ Second, ch14.18 directly activates the complement system on the tumor cell surface, leading to cell lysis by complement-dependent cytotoxicity (CDC) ${ }^{8}$ Since GD2 is expressed on sensory nerve fibers as well, ch14.18 binds to GD2 on 
sensory nerve fibers and activates the complement system locally, which generates anaphylatoxins such as C5a that can activate sensory neurons, thereby promoting pain. ${ }^{9}$ As complement activation is one of the mechanisms contributing to pain after ch14.18, attempts have been made to circumvent complement activation on peripheral nerves with GD2 antibodies. For example, the introduction of the K322A mutation in the IgG1 Fc region, resulted in reduced CDC. However, this K322A variant still induces neuropathic pain in patients. ${ }^{1011}$

We hypothesized that enhancing ch14.18-mediated activation of granulocytes is beneficial, while avoiding antibody-induced complement activation relieves pain observed in patients treated with ch14.18. This urged us to investigate IgA as an alternative isotype for ch14.18, since IgA is superior to IgG in activating granulocytes, while having no binding site for $\mathrm{C} 1 \mathrm{q}$, the first component of the classical complement pathway. ${ }^{12}$

\section{METHODS}

\section{Antibody production, isolation and quality control}

The variable heavy and light chain sequences of ch14.18 were derived from Biologic License Application 125516. The variable chain sequences were cloned into expression vectors (pEE14.4), coding for the IgA1 or IgG1 heavy chain or kappa light chain. Monomeric antibodies were produced by transient transfection of HEK293F cells with vectors coding for the heavy chain, light chain and pAdvantage (accession number U47294; Promega), using 293Fectin transfection reagent according to the manufacturer's instructions. IgG1 antibodies were purified using protein A columns (Hi-trap protein A) coupled to an ÄKTA prime plus chromatography system (GE Lifesciences). Bound antibody was eluted with $0.1 \mathrm{M}$ sodium acetate $\mathrm{pH} 2.5$ and neutralized with 1M TRIS-HCl $\mathrm{pH}$ 8.8. The eluate was dialyzed against phosphate-buffered saline (PBS). IgA1 antibodies were purified using kappa light chain affinity chromatography columns (HiTrap KappaSelect, GE Healthcare) and eluted with $0.1 \mathrm{M}$ glycine buffer $\mathrm{pH}$ 2.5. The eluate was applied on a sizeexclusion chromatography (SEC) column ran with PBS as mobile phase. The fractions containing monomeric IgA were collected and concentrated with a $100 \mathrm{KDa}$ spin column (Vivaspin 20, GE Healthcare). All antibodies were filtered over $0.22 \mu \mathrm{m}$ filters. Purity and stability of the antibodies was analyzed by HP-SEC (Yarra 3u SEC2000 column) with $100 \mathrm{mM}$ sodium phosphate, $150 \mathrm{mM}$ $\mathrm{NaCl} \mathrm{pH} 6.8$ as mobile phase with detection at $280 \mathrm{~nm}$.

\section{Fluorescent labeling of antibodies}

Purified antibodies were labeled with fluorescein by incubation at room temperature for 2 hours with N-hydroxysuccimidyl-FITC (Thermo Fisher) while stirring. Unbound NHS-fluorescein was removed by using sephadex columns (NAP-5, GE Healthcare), according to the manufacturer's instructions. Antibodies were labeled with
Alexa fluor-488 antibody labeling kit (Thermo Fisher) according to the manufacturer's instructions.

\section{Cell culture}

All neuroblastoma cell lines were acquired from the ATCC and cultured in Dulbecco"s modified Eagle's medium (DMEM) culture medium supplemented with HEPES, GlutaMAX, 10\% heat-inactivated fetal calf serum, $100 \mathrm{U} / \mathrm{mL}$ penicillin-streptomycin (Gibco Life Technologies) and 2\% non-essential amino acids (Thermo Fisher) at $37^{\circ} \mathrm{C}$ in a humidified incubator containing $5 \%$ carbon dioxide $\left(\mathrm{CO}_{2}\right)$. HEK293F cells were cultured in FreeStyle 293 expression medium at $37^{\circ} \mathrm{C}$ in a humidified incubator with orbital shaker platform containing $8 \% \mathrm{CO}_{2}$. Cells were not cultured past passage number 20 and comparisons between IgA and IgG were conducted paired to prevent bias between cell line batches. Cells were regularly tested for mycoplasma contamination by MycoAlert Mycoplasma Detection Kit (Lonza).

\section{Binding assays}

$1 \times 10^{5}$ neuroblastoma cells were plated out in 96 well plates and centrifuged for $2 \mathrm{~min}$ at 1500 RPM. Cells were washed and incubated with fluorescein-labeled antibody at several concentrations for $45 \mathrm{~min}$ on ice. Next, cells were centrifuged for $2 \mathrm{~min}$ at $1500 \mathrm{RPM}$, washed and resuspended in PBS. The amount of bound antibody to the cells was quantified by flow cytometry (BD FACSCanto II).

\section{Cell-based affinity measurements}

IMR-32 neuroblastoma cells were plated out on the side of a culture dish in an elliptical shape and incubated overnight for attachment to the plate. Subsequently, plates were washed with culture medium and transferred to the LigandTracer apparatus (Ridgeview Instruments). First, background signal of cells with medium was measured for $15 \mathrm{~min}$. Afterwards, association was measured for 1 hour at $10 \mathrm{nM}$ of antibody and subsequently at $20 \mathrm{nM}$ for 1 hour. Finally, dissociation was measured by replacing the antibody containing solution for antibody-free medium for 2 hours. The affinity of the antibodies was calculated via TraceDrawer software.

\section{ADCC assays}

ADCC was quantified as described previously. ${ }^{14}$ In short, target cells were labeled with ${ }^{51} \mathrm{Cr}$ (PerkinElmer). Afterwards, cells were washed. Blood for ADCC's was obtained from healthy donors at the UMC Utrecht (approval number $07-125 / \mathrm{O}$ ). For leukocyte isolation, blood was incubated in water for $30 \mathrm{~s}$ to lyse erythrocytes. Afterwards, $10 \times$ PBS was added to reach physiological osmolality. Cells were washed and resuspended. For polymorphonuclear cells (PMN) and peripheral blood mononuclear cell (PBMC) isolation, blood was added on top of a Ficoll (GE Healthcare)/Histopaque 1119 (Sigma) layer and centrifuged for $20 \mathrm{~min}$ at $1500 \mathrm{RPM}$. Afterwards, PBMCs and PMNs were collected from the interphase between serum and ficoll or in the histopaque layer, respectively. The 
used effector-to-target (E:T) ratios were 100:1 for PBMCs, 40:1 for PMNs. Effector cells with or without pretreatment of $10 \mu \mathrm{M}$ of 11-cis retinoic acid (Sigma), antibodies at various concentration, $10 \mathrm{ng} / \mathrm{mL}$ IL-2 $(650 \mathrm{IU} / \mathrm{mL})$ (eBioscience) and $10 \mathrm{ng} / \mathrm{mL}$ GM-CSF (ImmunoTools), $15 \%$ pooled human serum and tumor cells were added to round-bottom microtiter plates (Corning Incorporated) and incubated for $37^{\circ} \mathrm{C}$ in a humidified incubator containing $5 \% \mathrm{CO}_{2}$. Plates were centrifuged for $2 \mathrm{~min}$ at 1500 RPM and the supernatant was transferred to lumaplates (PerkinElmer). Radioactive scintillation (in cpm) was quantified in a beta-gamma counter (PerkinElmer). Specific lysis was calculated using the formula: ( (experimental cpm - basal cpm)/(maximal cpm - basal cpm) $\times 100$, with maximal lysis determined by incubating labeled cells with $1.25 \%$ triton and minimal lysis in the absence of antibodies and effector cells.

\section{Live cell imaging}

IMR-32 cells were seeded in an 8 well $\mu$-slide (Ibidi) 1 day prior to live cell imaging. Target cells were labeled with $20 \mu \mathrm{M}$ Calcein-AM according to the manufacturers protocol (Thermo Fisher). Subsequently, either $10 \mu \mathrm{g} /$ mL IgG1 ch14.18 or IgA2.0 ch14.18 and $1 \mu \mathrm{M}$ TO-PRO-3 (Thermo Fisher) were added to the target cells. Primary PMNs were labeled with eFluor 450 (Thermo Fisher) according to the manufacturers protocol and were added 15 min after antibodies treatment. Live-cell imaging recordings were performed with a Deltavision RT widefield microscope (GE Healthcare) housed in a conditioned, temperature-controlled $\left(37^{\circ} \mathrm{C}\right)$, humidified chamber containing $5 \% \mathrm{CO}_{2}$. Images were recorded using an Olympus $40 \times / 1.35 \mathrm{NA}$ oil immersion objective on a Cascade II 1K EMCCD/E2V CCD-201 camera. Imaging data was analyzed using Imaris (Bitplane).

\section{CDC assays}

$10^{5}$ neuroblastoma cells were added per well to 96 wells microtiter plates and incubated for $30 \mathrm{~min}$ with antibodies at various concentrations at room temperature. Afterwards, pooled human serum (from eight different healthy donors) was added to a concentration of $15 \%$ and incubated for 1 hour or 4 hours. Afterwards, cells were washed and stained with 7-AAD (BD Pharmingen) for 15 min. 7-AAD uptake, representing cell lysis was quantified by flow cytometry (FACSCanto II, BD Biosciences).

\section{C5a quantification}

MaxiSorp 96 well ELISA plates (NUNC) were coated with $10 \mathrm{ug} / \mathrm{ul}$ anti-GD2 antibody overnight at $4^{\circ} \mathrm{C}$. Afterwards, plates were washed and pooled human serum was added for $15 \mathrm{~min}$ or $60 \mathrm{~min}$ at $37^{\circ} \mathrm{C}$. Subsequently C5a was quantified by performing a C5a ELISA (R\&D systems) according to the manufacturers protocol.

\section{Antibody concentration determination in mouse serum}

MaxiSorp 96 well ELISA plates (NUNC, Thermo Fisher) were coated overnight with $0.5 \mu \mathrm{g} / \mathrm{mL}$ polyclonal goat IgG anti-human kappa (Southern Biotech) diluted in
PBS. Next, plates were washed three times with $0.05 \%$ TWEEN 20 in PBS (PBST) and blocked for 1 hour by incubating with $1 \%$ BSA (Roche) in PBST. Serum samples were diluted 1:2000 in 1\% BSA in PBST and incubated for 1.5 hours at room temperature. Next, plates were washed three times with PBST. HRP-labeled-anti-human IgA or HRP-labeled-anti-human-IgG (SouthernBiotech) were used to bind human IgA or human IgG, respectively. Plates were developed for 10 min with ABTS (Roche) and read out on a spectrophotometer (Bio-Rad) at $415 \mathrm{~nm}$.

\section{Animals and animal experiments}

Mice were maintained in the animal facility of the University of Utrecht. Experiments were conducted using both male and female C57BL/6JRj mice (Janvier)

For evaluating the in vivo efficacy of antibodies, mice were intraperitoneally (i.p.) injected with $5 \times 10^{6}$ GD2 expressing EL4 cells expressing Luc2. After 1 day, mice were i.p. injected with $100 \mu \mathrm{g}$ of IgG1 ch14.18, or $100 \mu \mathrm{g}$ of IgA1 ch14.18. After 2 days, blood was taken and mice were injected with $100 \mu \mathrm{l}$ of $0.025 \mathrm{~g} / \mathrm{mL}$ luciferin (Promega) i.p. and subjected to bioluminescence analysis 1 min after injection with 5 min exposure time to quantify tumor cells (PhotonImager, Biospace Lab). Image analysis was performed using M3Vision software (Biospace Lab). Afterwards mice were euthanized by cervical dislocation. In a second model, mice were intravenously (i.v.) injected with $1 \times 10^{6}$ cells and treated i.p. with $100 \mu \mathrm{g}$ IgG1 ch14.18 or $100 \mu \mathrm{g}$ IgA1 ch14.18. After 2 days, mice were retreated with antibodies. After 24 hours, blood was taken and mice were injected with luciferin and subjected to bioluminescence analysis to quantify tumor cells.

Mechanical thresholds were determined using the von Frey test (Stoelting) with the up-and-down method as was described before. ${ }^{1516}$ In brief, mechanical allodynia was assessed with calibrated von Frey hair monofilaments (Stoelting). First, mice were acclimated for 15-20 min in a transparent box with a metal mesh floor. Mice were i.v. treated with $100 \mu \mathrm{g}$ of IgG1 isotype control, $4 \mu \mathrm{g}$ or $20 \mu \mathrm{g}$ of IgG1 ch14.18, or 20 and $100 \mu \mathrm{g}$ of IgA1 ch14.18. The von Frey hair monofilaments were applied through the mesh floor to the plantar skin of the hind paw. The hair force was increased or decreased according to the response. Clear paw withdrawal, shaking or licking were considered as nociceptive-like responses. In each experiment, the average of the left and right paw was considered as an independent measure. To minimize bias, animals were randomly assigned to the different groups prior to the start of experiment, and all experiments were performed by experimenters blinded to treatment. Von Frey data was obtained from separate experiments. Equivalent dosing in pain experiments was based on data from previous studies. ${ }^{17}$

Antibody binding to neurons was visualized by i.v. injection of 20 or $100 \mu \mathrm{g}$ alexa-488 labeled IgG1 ch14.18 or $100 \mu \mathrm{g}$ of IgA1 ch14.18. Sciatic nerves were isolated and $10 \mu \mathrm{m}$ thick slices were prepared with a cryostat cryotome and placed on slides. Slides were fixed for $10 \mathrm{~min}$ in 
4\% paraformaldehyde (PFA) and washed. Finally, slides were counterstained with 4',6-diamidino-2-phenylindole (DAPI), washed and treated with FluorSave (Calbiochem). Slides were dried overnight at $4^{\circ} \mathrm{C}$ and images were taken by fluorescence microscopy (Zeiss).

C4 deposition was determined by immunofluorescence on mouse sciatic nerves. Slides were fixed in $4 \%$ PFA, washed and incubated with $10 \mathrm{mM}$ ammonium chloride in PBS. After washing, slides were incubated with $10 \mu \mathrm{g} / \mathrm{mL}$ of IgG1 ch14.18 or IgA1 ch14.18 for 1 hour. Slides were washed and incubated with $15 \%$ pooled human serum or heat-inactivated serum for 1 hour at room temperature. Afterwards, slides were washed and incubated with biotin conjugated polyclonal anti-human C4 antibody (MyBioSource). For detection, slides were incubated with alexa-594 conjugated to streptavidin (Thermo Fisher Scientific). Finally, slides were counterstained with DAPI by incubation with ProLong diamond antifade mountant (Thermo Fisher Scientific). Fluorescence quantification was performed with Image J.

\section{Data processing and statistical analysis}

Statistical analyses were performed in GraphPad Prism V.7.0 software (GraphPad). Data are represented as mean \pm SD. For comparing mean values of two groups, an unpaired two-tailed Student's t-test was performed. For multiple comparisons, two-tailed one-way analysis of variance (ANOVA) was performed with Tukey's range test. For multiple comparisons with multiple concentrations, two-tailed two-way ANOVA was performed with Sidak's multiple comparisons test. Dose-response curves for ADCC experiments were calculated via non-linear regression using GraphPad V.7.0 software. Asterisks were used to indicate statistical significance: ${ }^{*} p<0.05$, $* * p<0.01, * * * p<0.001$ or n.s. if no statistical significance was obtained.

\section{RESULTS \\ IgA1 and IgG1 ch14.18 specifically bind GD2 with similar affinity}

First, we determined the binding of IgA1 and IgG1 ch14.18 to neuroblastoma cell lines. IgA1 and IgG1 antibodies with the ch14.18 variable region were produced and purified in-house. All antibodies were monomeric, with a purity above $95 \%$ (online supplemental figure 1). Both antibodies bound similarly to the GD2 expressing neuroblastoma cell line IMR-32, while the GI-ME-N cell line without GD2 expression was not recognized (figure 1A). To investigate whether the affinity of the antibodies is independent of the isotype, real time cell-based affinity measurements on IMR-32 cells were performed with LigandTracer. The IgG1 and IgA1 antibodies closely follow the same association pattern at two different concentrations and overlapped in the dissociation phase, showing that the affinity of both isotypes do not differ significantly $(3.8 \pm 0.3 \mathrm{nM}$ vs $4.8 \pm 0.5 \mathrm{nM}$ ) (figure $1 \mathrm{~B}, \mathrm{C}$ ).

\section{Mechanism of action of IgA1 and IgG1 ch14.18 antibodies}

Subsequently, we compared the in vitro mechanisms of action of IgA1 and IgG1 ch14.18. To compare killing of neuroblastoma with a mix of effector cells, ADCC assays were performed on IMR-32, SK-N-FI and LAN-5 neuroblastoma cell lines, with leukocytes from peripheral blood as effector cells. LAN-5 cells showed the highest binding of ch14.18 IgA, followed by IMR-32, SK-N-FI and GI-ME-N (online supplemental figure 1C). Both IgA1 and IgG1 antibodies lysed IMR-32 cells to a similar extent, while SK-N-FI and LAN-5 cells were killed better with IgA1 ch14.18 compared with IgG1 (figure 2A). The GI-ME-N cell line which has no detectable GD2 expression, was not lysed by either antibody, showing that GD2 expression is a prerequisite for ch14.18-mediated ADCC (online supplemental figure $2 \mathrm{~A}$ ).

To evaluate the relative contribution of leukocyte subsets in mediating ADCC against neuroblastoma cell lines, isolated neutrophils or PBMC from healthy donors were separately used as effector cells. IgG1 ch14.18 effectively induced lysis in neuroblastoma cell lines with PBMCs as effector cells, while the IgA antibody did not lyse these cells (figure 2B, online supplemental figure 2B). Conversely, when neutrophils were used as effector cells, IgA ch14.18 mediated ADCC was superior for all tested cell lines in comparison to IgG1 (figure 2C, online supplemental figure 2C). These observations were also confirmed by in vitro imaging experiments, showing rapid engulfment and killing of IMR32 cells by neutrophils when treated with IgA anti-GD2, while this process was slower and inefficient with IgG1 anti-GD2 (figure 2D).

In patients, ch14.18 is administered as combination therapy with GM-CSF, IL-2 and retinoic acid. Therefore, the impact of these compounds on ADCC was assessed. Addition of GM-CSF did not increase ADCC by IgG1, when PBMCs were used as effector cells. Addition of the combination of GM-CSF and IL-2 led to a small increase of cell death without the presence of antibody, showing increases in PBMC-mediated killing of neuroblastoma regardless of antibody. GM-CSF and IL-2 did not affect maximal killing by PBMC-mediated ADCC by IgG1, but improved killing at lower concentrations. Pre-exposure of target cells to 11-cis retinoic acid for 24 hours to the previous combination further increased the IgG1independent and IgG1-dependent killing of neuroblastoma cell lines (figure 2E, online supplemental figure 2D). IgA1 did not induce killing by PBMCs, but neuroblastoma cells were lysed in the presence of IL-2 alone or in combination with 11-cis-retinoic acid, indicating antibody-independent recognition of neuroblastoma cells by PBMCs (online supplemental figure 2E).

With neutrophils as effector cells, GM-CSF in combination with IgA1 or IgG1 ch14.18 boosted ADCC (figure 2F, online supplemental figure $2 \mathrm{~F}$ ), while combination with GM-CSF and IL-2 did not further improve GM-CSF enhanced neutrophil mediated killing. Pre-exposure of target cells with 11-cis-retinoic acid increased maximal lysis. In contrast to IgA1, IgG1-mediated ADCG with 


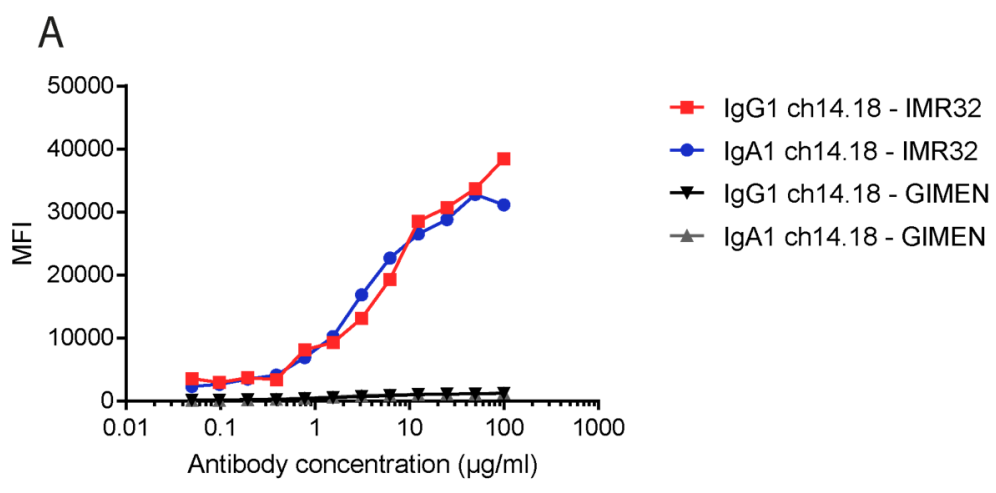

B

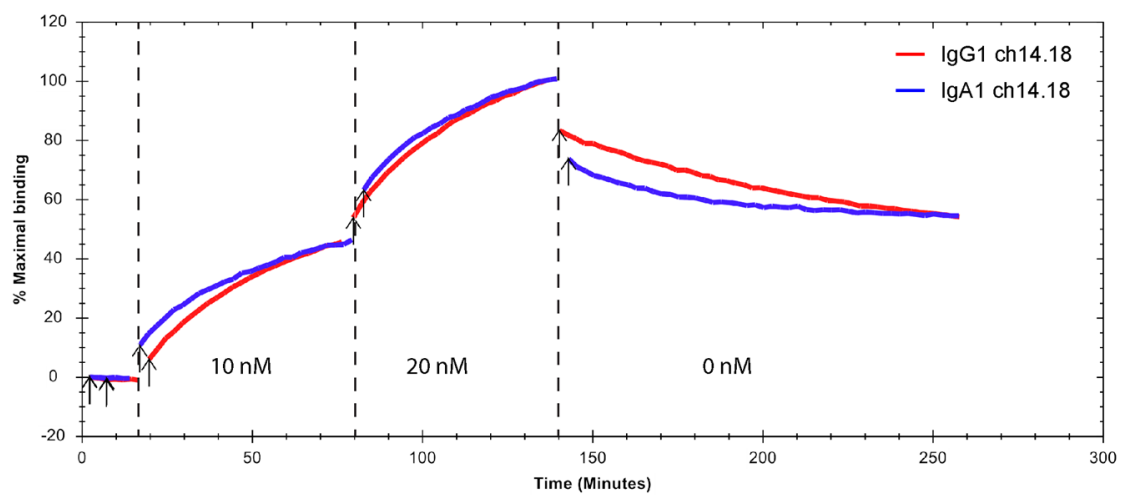

C

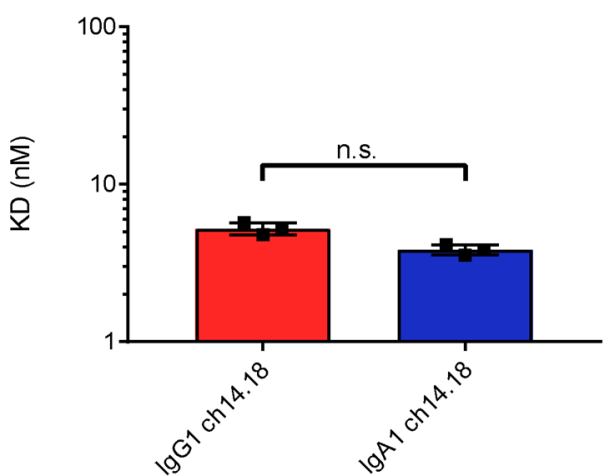

Figure 1 Binding of $\lg \mathrm{G} 1$ and $\lg A 1$ ch14.18 antibodies to neuroblastoma cell lines. (A) Flow cytometric assessment of antibody binding of IgA1-FITC and IgG1-FITC ch14.18 to GD2-expressing neuroblastoma cell line IMR-32 and GD2-negative cell line GIME-N. (B) Real-time cell-based affinity measurement of FITC-labeled IgA1 and IgG1 ch14.18 on IMR-32 cells. IMR-32 cell lines were treated with $10 \mathrm{nM}$ of antibody. Subsequently, antibody concentration was increased to $20 \mathrm{nM}$ of antibody. Dissociation was followed for 2 hours. The traces show the fluorescent signal of three individual measurements per antibody (IgG1 in red, IgA1 in blue,). (C) Calculated affinities from cell-based affinity measurements shown in B using one-to-one fitting. Data show mean affinity $\pm S D$ ( $n=3$, technical triplicate). MFI, mean fluorescent intensity; FITC, fluorescein isothiocyanate; n.s., no statistical significance.

neutrophils was only improved slightly by GM-CSF. Furthermore, addition of IL-2 or retinoic acid did not further enhance killing (online supplemental figure $2 \mathrm{G}$ ).

\section{IgA1 ch14.18 does not trigger complement activation}

Ch14.18 lyses neuroblastoma target cells via CDC in vitro, however, the same complement activation is at least partially responsible in vivo for inducing treatmentassociated pain on sensory neurons expressing GD2. Therefore, we assessed in vitro complement activation by these antibodies on a panel of neuroblastoma cell lines. As expected, IgG1 ch14.18 induced CDC on GD2expressing neuroblastoma cell lines within $15 \mathrm{~min}$. In contrast, no complement-mediated lysis was observed for IgA1 ch14.18 (figure 3A). With longer incubation for 4 hours, the amount of lysis further increased for IgG1, but remained similarly low for IgA1 (figure $3 \mathrm{~B}$ ). The neuroblastoma cell line SK-N-FI expressed more complement regulatory proteins than the other tested neuroblastoma cell lines, potentially explaining its resistance against complement mediated lysis (online supplemental 
A

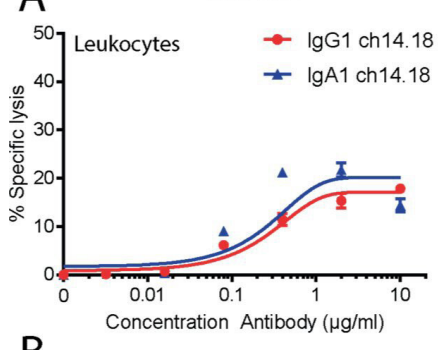

B

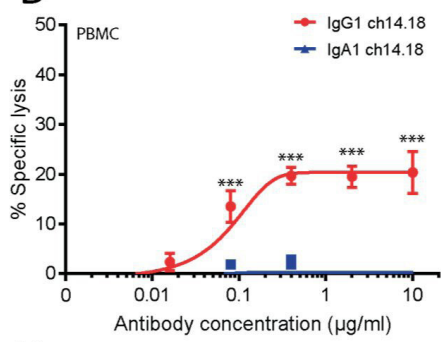

$\mathrm{D}$
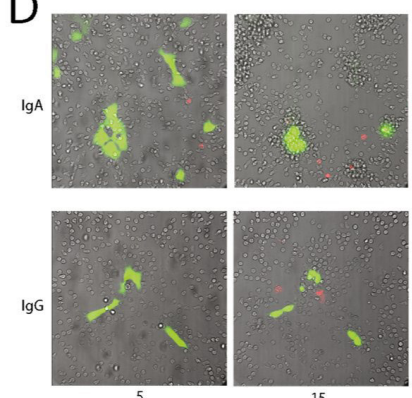

$\mathrm{E}$
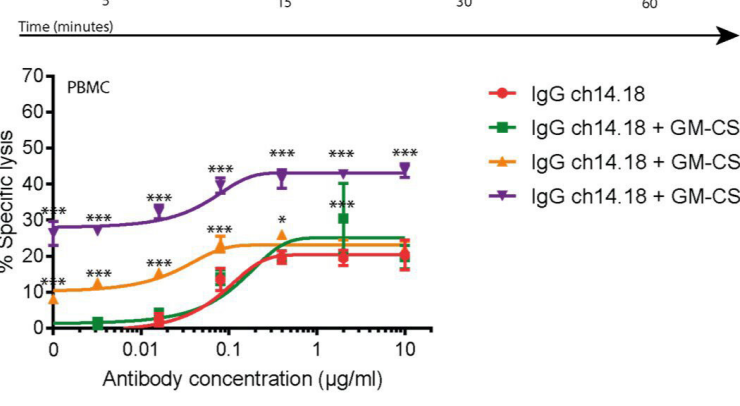

$\mathrm{F}$

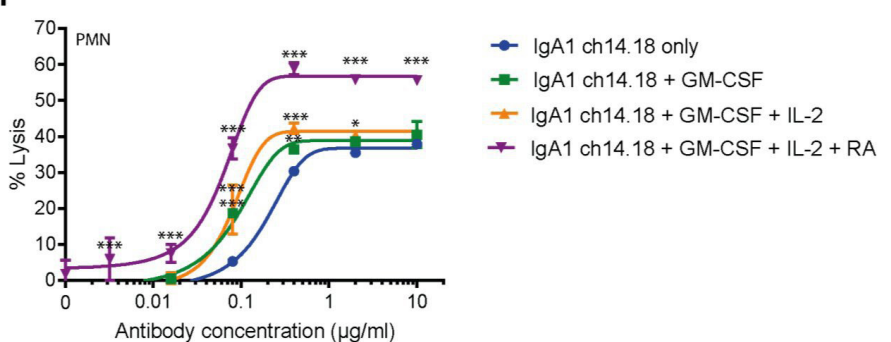

$\rightarrow \operatorname{IgG} \operatorname{ch} 14.18+\mathrm{GM}-\mathrm{CSF}+\mathrm{IL}-2+\mathrm{RA}$
SK-N-FI
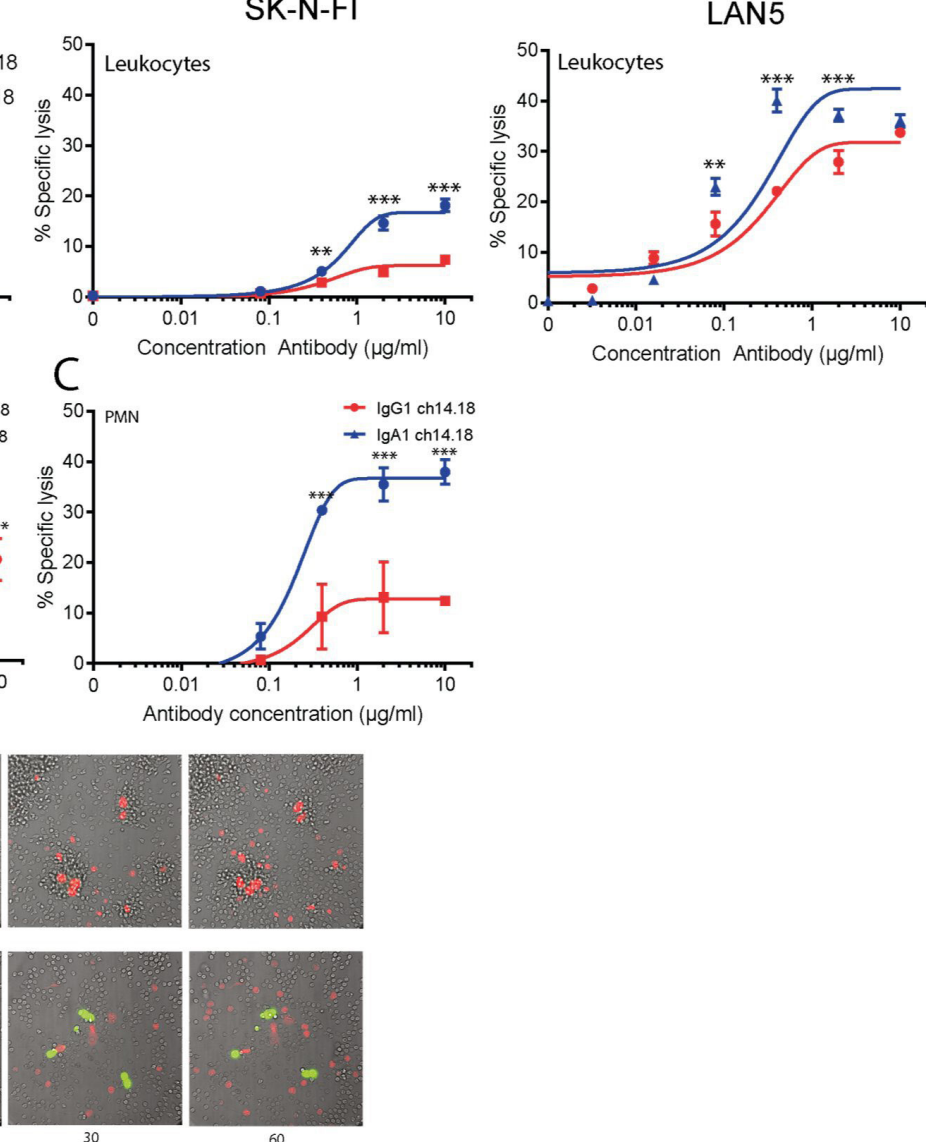

$\rightarrow \lg G \operatorname{ch} 14.18$

$=\lg \mathrm{ch} 14.18+\mathrm{GM}-\mathrm{CSF}$

$+\operatorname{lgG} \operatorname{ch} 14.18+\mathrm{GM}-\mathrm{CSF}+\mathrm{IL}-2$

Figure 2 Induction of ADCC by IgA1 and IgG1 ch14.18 against neuroblastoma cell lines. (A) ADCC assays with IgA1 and IgG1 ch14.18 on three different neuroblastoma cell lines with leukocytes from blood as effector cells. (B) ADCC assays with IgG1 and IgA1 ch14.18 on neuroblastoma cell line IMR-32 with isolated PBMCs (E:T ratio of 100:1) as effector cells. (C) ADCC assays with IgG1 and IgA1 ch14.18 on IMR-32 neuroblastoma cell line with isolated neutrophils (E:T ratio of 40:1) as effector cells. (D) Livecell imaging of PMN-mediated ADCC. Calcein-AM labeled IMR-32 cells (Green) were treated with $10 \mu \mathrm{g} / \mathrm{mL} \mathrm{IgG1}$ ch14.18 or IgA ch14.18. eFluor450-labeled PMNs were added at an 83:1 E:T ratio to tumor cells. Cell death was visualized with TOPRO-3 (Red). (E) ADCC assays with IgG1 ch14.18 on IMR-32 neuroblastoma cell line with isolated PBMCs (E:T ratio of 100:1) as effector cells with or without co-treatment of GM-CSF, IL-2 and 11-cis retinoic acid. (F) ADCC assays as in (E) with IgA1 ch14.18 with isolated neutrophils (E:T ratio of 40:1) as effector cells. All ADCC assays were incubated for 4 hours at $37^{\circ} \mathrm{C}$. Data represent mean lysis of a representative donor $\pm S D$ (technical triplicate at least $n=3$ donors per assay). Statistical significance was determined by two-way analysis of variance. ADCC, antibody-dependent cell-mediated cytotoxicity; E:T, effector-to-target; IL, interleukin; RA, 11-cis retinoic acid; GM-CSF, granulocyte-macrophage colony-stimulating factor; PMN, polymorphonuclear cells; PBMC, peripheral blood mononuclear cells. 

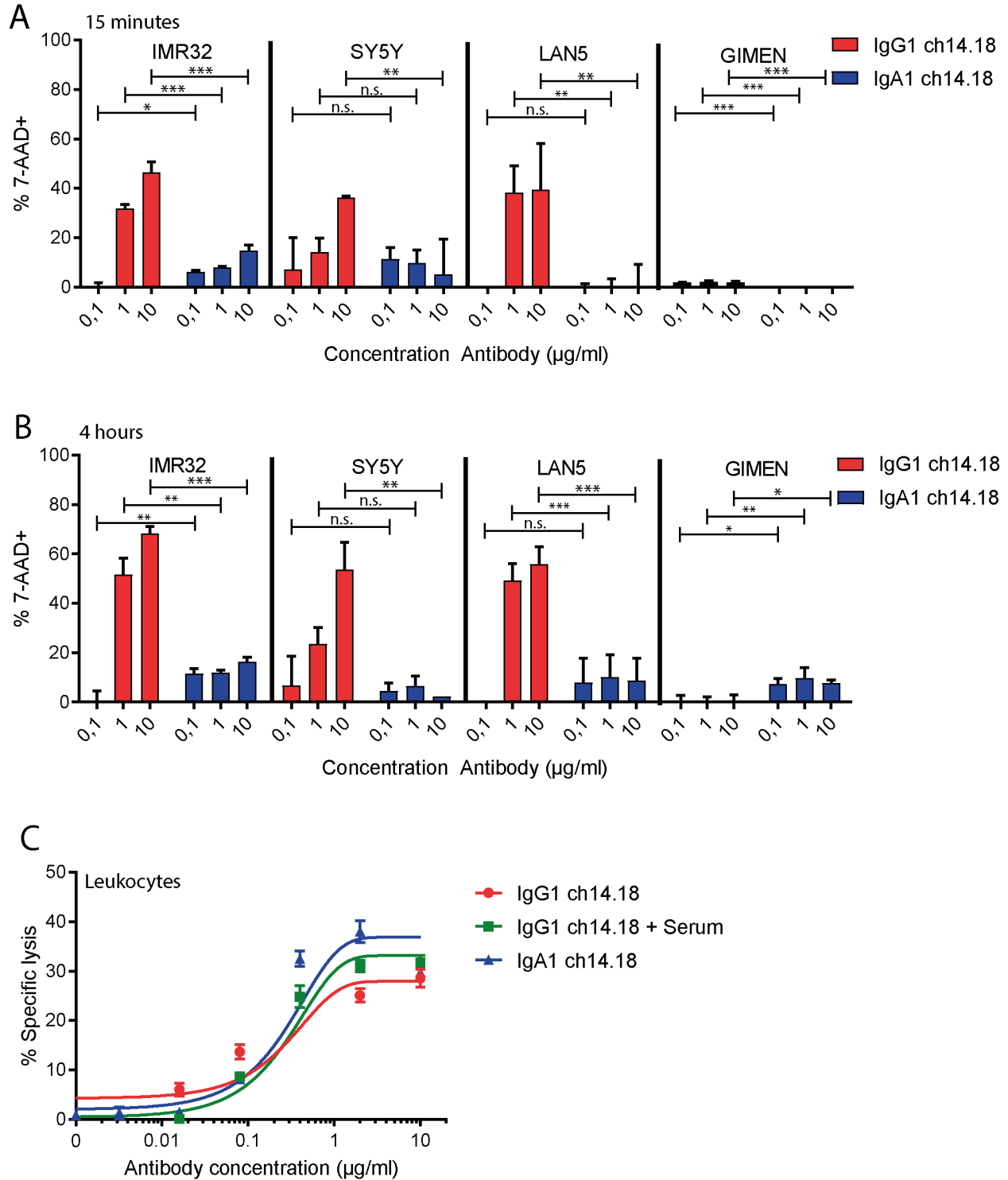

$\mathrm{D}$

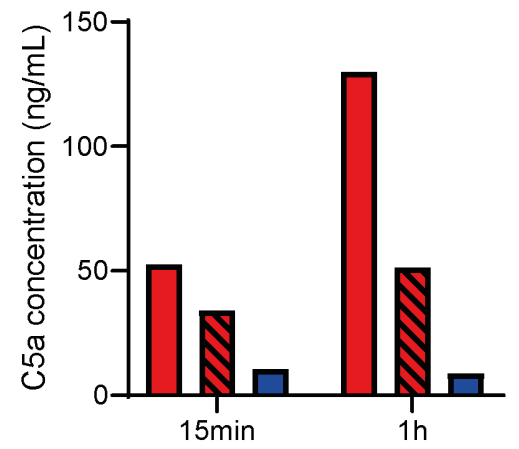

口 $\operatorname{lgG} 1 \mathrm{ch} 14.18$
Ш $\operatorname{lgG} 1 \mathrm{ch} 14.18$ K322A
口 $\operatorname{lgA} 1 \mathrm{ch} 14.18$

Figure 3 Complement assays on a panel of neuroblastoma cell lines by $\lg \mathrm{G} 1$ and $\lg A 1$ ch14.18 antibodies. (A) Lysis by IgG1 or IgA1 ch14.18 antibodies on four different neuroblastoma cell lines. Cells were incubated with three different concentrations of antibody for $30 \mathrm{~min}$ and subsequently with $15 \%$ pooled human serum for $15 \mathrm{~min}$. Data represents mean percentage of $7-A A D+c e l l s \pm S D(n=3)$. (B) Lysis by IgG1 or IgA1 ch14.18 antibodies on four different neuroblastoma cell lines. Cells were incubated with three different concentrations of antibody for $30 \mathrm{~min}$ and subsequently with $15 \%$ pooled human serum for 4 hours. Data represents mean percentage of $7-A A D+c e l l s \pm S D(n=3)$. Statistical significance was determined by two-way analysis of variance. (C) ADCC assays with IgA1 ch14.18 or IgG1 ch14.18 with or without $15 \%$ serum on IMR-32 neuroblastoma cell line and with leukocytes from peripheral blood as effector cells. Data represent mean $\pm S D$. (D) C5a quantification in pooled human serum after incubation with plate-bound antibody for $15 \mathrm{~min}$, or $60 \mathrm{~min}$. Data show a representative example $(n=3)$. 
figure 3A,B). Additionally, we investigated whether IgGmediated CDC increased neuroblastoma cell lysis when combined with ADCC by mixed leukocytes. No significant increases in lysis were observed on IMR32 cells after addition of serum (figure 3C). Recently, an engineered IgG1 antibody (K322A) with reduced complement activation has entered clinical trials. ${ }^{10}$ As a different measure of complement activation, we quantified C5a generation in serum by plate bound IgG1, IgG1 K322A and IgA ch14.18. Interestingly, IgG1 ch14.18 K322A generated less C5a compared with the wild type IgG1 antibody, but IgA ch14.18 showed even less C5a formation (figure 3D). While C5a generation increased for both IgG ch14.18 antibodies over time, this was absent with IgA ch14.18.

\section{IgA1 ch14.18 performs tumor cell killing in vivo}

Next, we analyzed the capacity of the IgG1 and IgA1 antibodies to kill GD2 expressing cells in vivo in two syngeneic immune-competent mouse models. As a model for a localized tumor, human CD89 transgenic $\mathrm{C} 57 \mathrm{Bl} / 6$ mice were i.p. injected with EL4 cells, which naturally express GD2. CD89 transgenic mice express CD89 under the endogenous promotor, thereby limiting expression to granulocytes and activated monocytes and macrophages. ${ }^{18}$ After 24 hours of outgrowth, animals were treated with IgA1 or IgG1. Outgrowth of tumor cells was evaluated 24 hours after injection of the antibody by bioluminescent analysis (figure 4A). Both IgA and IgG treatment resulted in killing of tumor cells, although not significant (figure 4B,C).

In a second systemic tumor mouse model, EL4 cells were i.v. injected, and treatment was injected i.p. (figure 4D). After 3 days of treatment, both IgA1 and IgG1 cleared the tumor cells, while tumor cells were still present in mice treated with PBS (figure 4E,F).

\section{IgA1 does not activate complement on neurons in vivo and does not induce pain}

A major limitation of IgG1 antibodies directed against GD2 is the induction of pain and allodynia after treatment. Similarly, systemic administration of GD2 antibodies increases mechanical sensitivity (allodynia) in rats. ${ }^{11}$ To test whether the lack of complement activation by IgA would halt the development of pain by administration of an GD2 antibody, we tested allodynia development after antibody administration in vivo in mice.

To control for differences between the half-life of IgA1 and IgG1, mice were i.v. injected with either a subtherapeutic dose of IgG1 $(4 \mu \mathrm{g})$, corresponding to the serum levels of a dose of $20 \mu \mathrm{g}$ of IgA1 at 3 hours or a therapeutic dose of IgG1 $(20 \mu \mathrm{g})$ or IgA1 $(100 \mu \mathrm{g})$ (figure 5A). In line with the clinical phenotype after ch14.18 treatment and rat studies, treatment with $20 \mu \mathrm{g}$ of IgG1 ch14.18 elicited mechanical hypersensitivity in mice, that peaked 6 hours after administration and slowly returned to baseline (figure 5B). Four $\mu \mathrm{g}$ of IgG1 did not elicit mechanical hypersensitivity. Conversely, most doses of IgA1 did not affect paw withdrawal threshold, except for $100 \mathrm{ug}$ at 6 and 24 hours that slightly reduced thresholds but the reduction was threefold less than with $20 \mathrm{ug}$ IgG. Thus, IgA1 does not induce allodynia at levels that would be therapeutic for IgG1. IgA also did not reduce mechanical threshold in mice that express FcoR, indicating that mice able to perform tumor killing with IgA still do not develop pain after IgA administration (figure 5C). Subsequently, mice were injected with fluorescently-labeled GD2 antibodies. Fluorescently-labeled IgG1 ch14.18 reduced the withdrawal threshold while IgA1 did not (figure 5D). We visualized the in vivo binding of the GD2 antibodies to sensory neurons in the sciatic nerve ex vivo. Antibody exposure was observed with $20 \mu \mathrm{g}$ of IgG1 and $100 \mu \mathrm{g}$ of IgA1 ch14.18 to a similar extent and corresponded to the amount of antibody present in the serum (figure 5E). Ex vivo staining of GD2 on sciatic nerves overlapped with the signal from directly labeled antibodies. The isotype control (rituximab) did not bind sciatic nerves. Finally, we assessed ex vivo complement activation on sciatic nerves from naïve mice. IgG1 ch14.18 elicited C4 deposition, while no $\mathrm{C} 4$ deposition was observed when heat-inactivated serum was used. With IgA1 ch14.18 no C4 deposition was observed (figure $5 \mathrm{~F}$ ). Our results summarized in figure 6 , provide a novel approach to halt GD2 antibody-induced neuropathic pain and improve neutrophil-mediated killing of neuroblastoma.

\section{DISCUSSION/CONCLUSION}

The approval of ch14.18 for high-risk neuroblastoma led to improvements in the survival of patients with neuroblastoma. Nevertheless, IgG1 antibody therapy for neuroblastoma comes with a major limitation: severe pain caused in part through complement activation by the antibody on GD2-expressing neurons. We hypothesized that changing the isotype of ch14.18 from IgG1 to IgA1 leads to increased activation of neutrophils against neuroblastoma while abrogating antibody-induced pain. Our results show that IgA1 ch14.18 offers strong antitumoral effects through neutrophil-mediated ADCC without inducing allodynia in vivo.

Thus far two approaches were undertaken to amend the side effects of ch14.18, which focused on means to reduce complement activation or binding to GD2expressing neurons. A first approach to mitigate pain was to mutate the C1q-binding site of a humanized variant of ch14.18 (K322A) to abrogate antibody-mediated complement activation. ${ }^{11}{ }^{19}$ Lysine on position 322 in the IgG1 Fc-region is essential for interaction with C1q. Although reducing the affinity to $\mathrm{Clq}$ with a single amino acid mutation is possible, the Clq-binding site in the IgG1 Fc compromises multiple amino acids. ${ }^{20}$ Therefore, this approach only partially reduced complement activation, and as such systemic administration of hu14.18K322A in rats did not completely abrogate antibody-induced pain. ${ }^{11}$ Similarly, in a phase I clinical trial with this antibody, grade 3-4 pain still occurred in $68 \%$ of patients, which was dose limiting in $11 \%$ of patients. ${ }^{10} 21$ We show here that IgA ch14.18 does not initiate complement activation, since no 
A

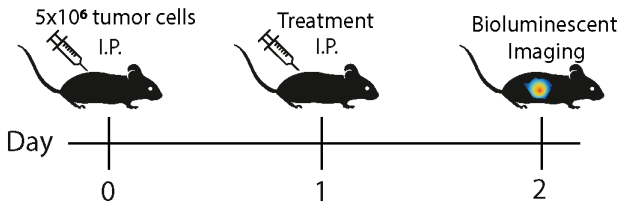

B
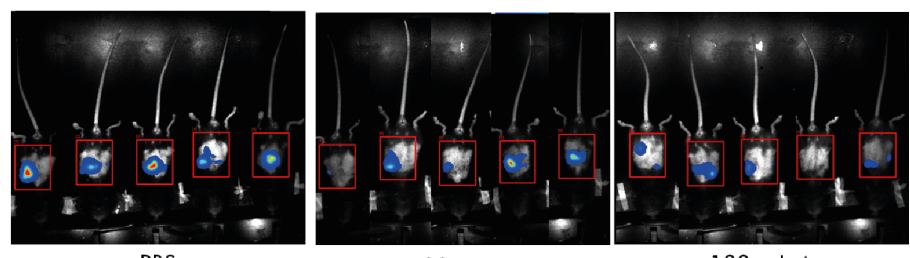

PBS

$100 u g \lg G$

$100 u g \lg A$

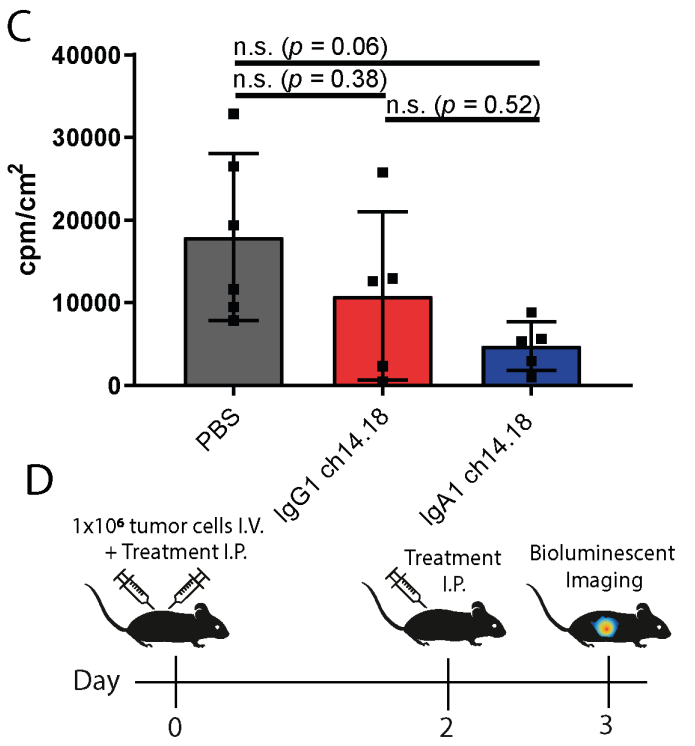

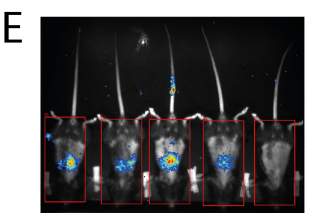

PBS

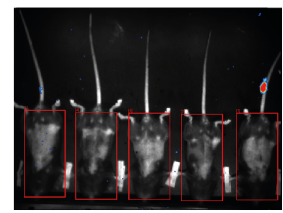

$\lg \mathrm{G} 100 \mu \mathrm{g}$

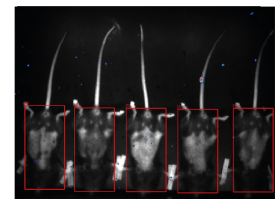

$\lg A 100 \mu \mathrm{g}$

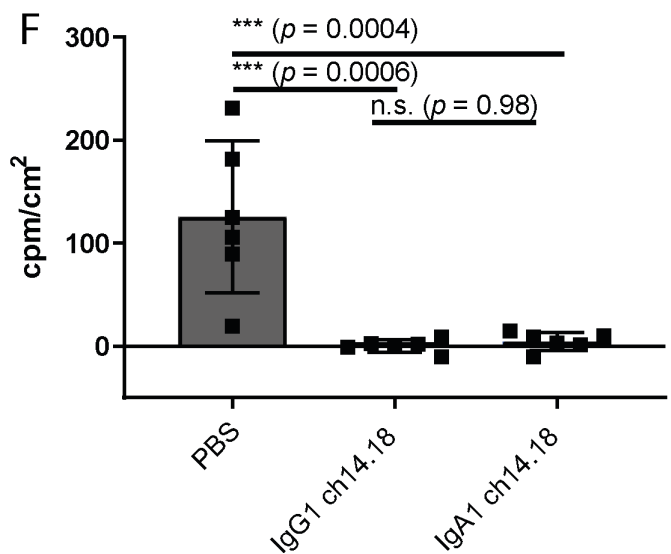

Figure 4 In vivo efficacy of IgG1 and IgA1 ch14.18 antibodies. (A) Graphical representation of treatment schedule of mice used in short IP model. (B) Bioluminescent imaging of EL4-Luc2 tumor cells after 24 hours of treatment with PBS, IgA1 or IgG1 ch14.18. (C) Quantification of bioluminescent signal in B. Data represents mean counts $/ \mathrm{cm}^{2}-$ background $\pm S D$ of at least five mice. Statistical significance was determined by one-way analysis of variance (ANOVA) with Tukey's post-hoc correction. (D) Graphical representation of treatment schedule of mice used in i.v. model. (E) Bioluminescent imaging of EL4-Luc2 tumor cells on day 3 of treatment after i.v. injection of tumor cells. (F) Quantification of bioluminescent signal after 3 days of treatment. Data represents mean counts $/ \mathrm{cm}^{2}$ - background $\pm S D$ of six mice per group. Statistical significance was determined by one-way ANOVA. i.p., intraperitoneally; i.v., PBS, phosphate-buffered saline; n.s., no statistical significance. 


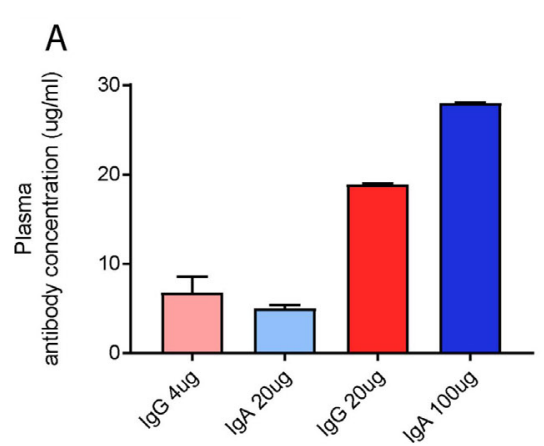

B

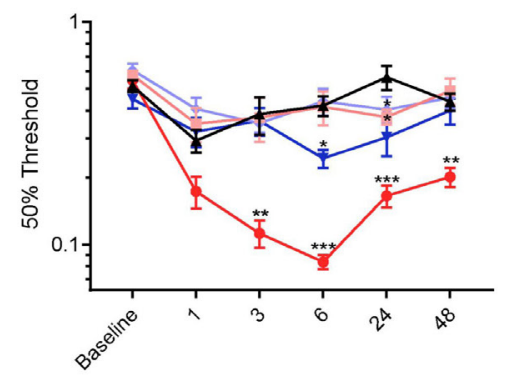

Time (hours)

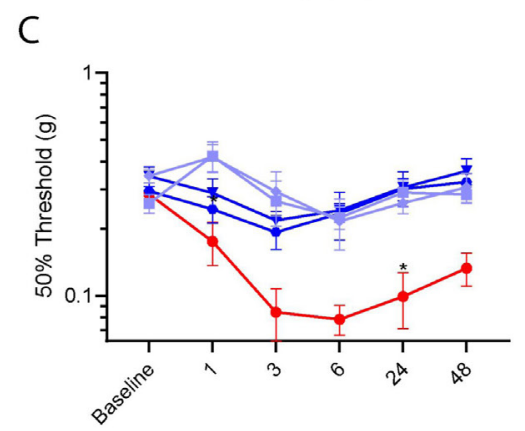

D

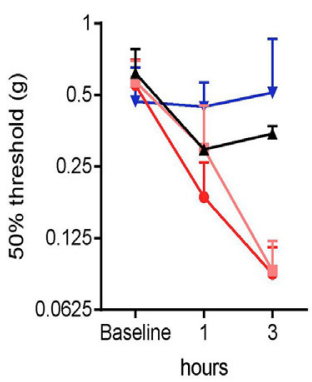

- IgG1 isotype control - - IgG1 ch14.18 $100 \mu \mathrm{g} \quad 100 \mu \mathrm{g}$

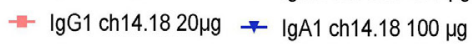
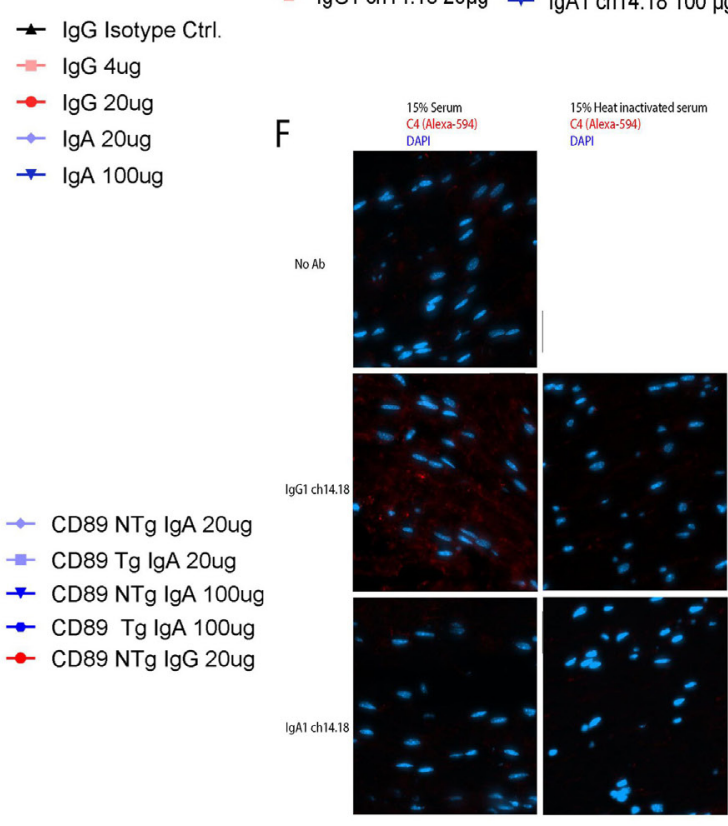

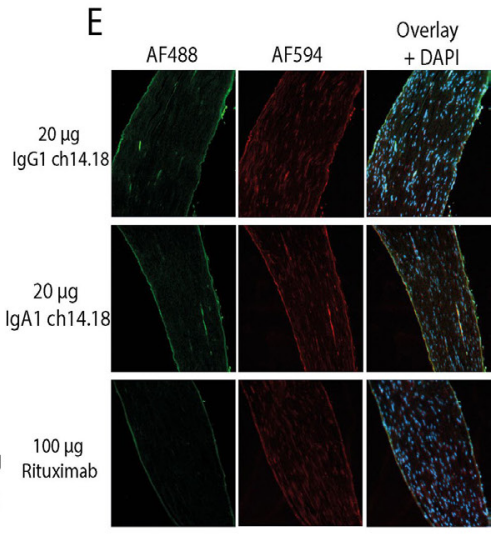

G

Figure 5 Neuronal exposure of to IgA1 does not lead to decreases in mechanical withdrawal thresholds nor C4 deposition. (A) Plasma concentrations of IgA1 and IgG1 ch14.18 3 hours after i.v. injection determined by ELISA. Data represents mean antibody concentration in $\mu \mathrm{g} / \mathrm{ml} \pm \mathrm{SD}$ of at least two mice per group. (B) Course of mechanical sensitivity as determined with von Frey test over time after i.v. injection of $\lg A 1$ or $\lg \mathrm{G} 1 \mathrm{ch} 14.18$. Data represents mean $50 \%$ withdrawal thresholds $\pm \mathrm{SEM}$ of at least eight mice per group. Statistical significance was determined by repeated measures analysis of variance (ANOVA) followed by Sidak's post-hoc analyses. (C) Von-Frey withdrawal thresholds over time after i.v. injection of IgA1 or IgG1 ch14.18 in mice expressing FcoR (CD89 Tg) or control littermate (NTg) mice. Data represents mean withdrawal thresholds \pm SEM of at least five mice per group pooled from separate experiments. Statistical significance was determined by repeated repeatedmeasures ANOVA followed by Sidak's post-hoc analyses. (D) Mechanical sensitivity as determined with von Frey test over time after i.v. injection of IgA1-AF488 or IgG1-AF488 ch14.18. Data represents mean withdrawal thresholds \pm SEM of at least two mice per group. (E) Left column: Visualization of intravenously injected Alexa-488 labeled GD2 antibodies on sciatic nerves. Middle column: Visualization of ex-vivo staining of GD2 by incubation of sciatic nerve slides with Alexa-549 labeled IgG1 ch14.18. Right column: Overlay (F) Visualization of ex vivo C4 fixation on sciatic nerves by IgG1 and IgA1 ch14.18 with complement active or heat-inactivated mouse serum. (G) Quantification of C4 deposition from F. i.v., intravenously.

CDC and C5a activation by IgA ch14.18 was observed in our assays. More importantly, systemic administration of IgA that effectively killed neuroblastoma cells in mice, did not elicit any signs of allodynia indicating that switching to IgA is an effective means to prevent severe side effects of IgG1 ch14.18. The second approach to circumvent ch14.18 induced allodynia was performed by targeting a different variant of GD2 (O-acetyl-GD2) with the antibody c.8B6. O-acetyl-GD2 is solely present on neuroblastoma cells and not on peripheral nervous tissue. ${ }^{22}$ Although c.8B6 does not bind pain fibers, the expression of O-acetyl-GD2 is twice as low on neuroblastoma cell lines and tissue and is therefore expected to be less efficacious in patients.

Regarding the effector mechanism, the IgG1 isotype suboptimally activates neutrophils against neuroblastoma, which might limit its effectiveness. Our data and data of others show that IgA is superior to IgG1 in activating neutrophils, which could be explained by the differential expression of Fc receptors on neutrophils. ${ }^{23}$ Human neutrophils express only one Fc $\alpha$ R, but 2 Fc $\gamma$ Rs: Fc $\gamma$ RIIIb and Fc $\gamma$ RIIa. Fc $\gamma$ RIIIb is exclusively expressed on neutrophils and is the most abundant FcR on these cells. FcyRIIIb is an GPI-linked molecule and binding of 
Mechanism of action | neuroblastoma

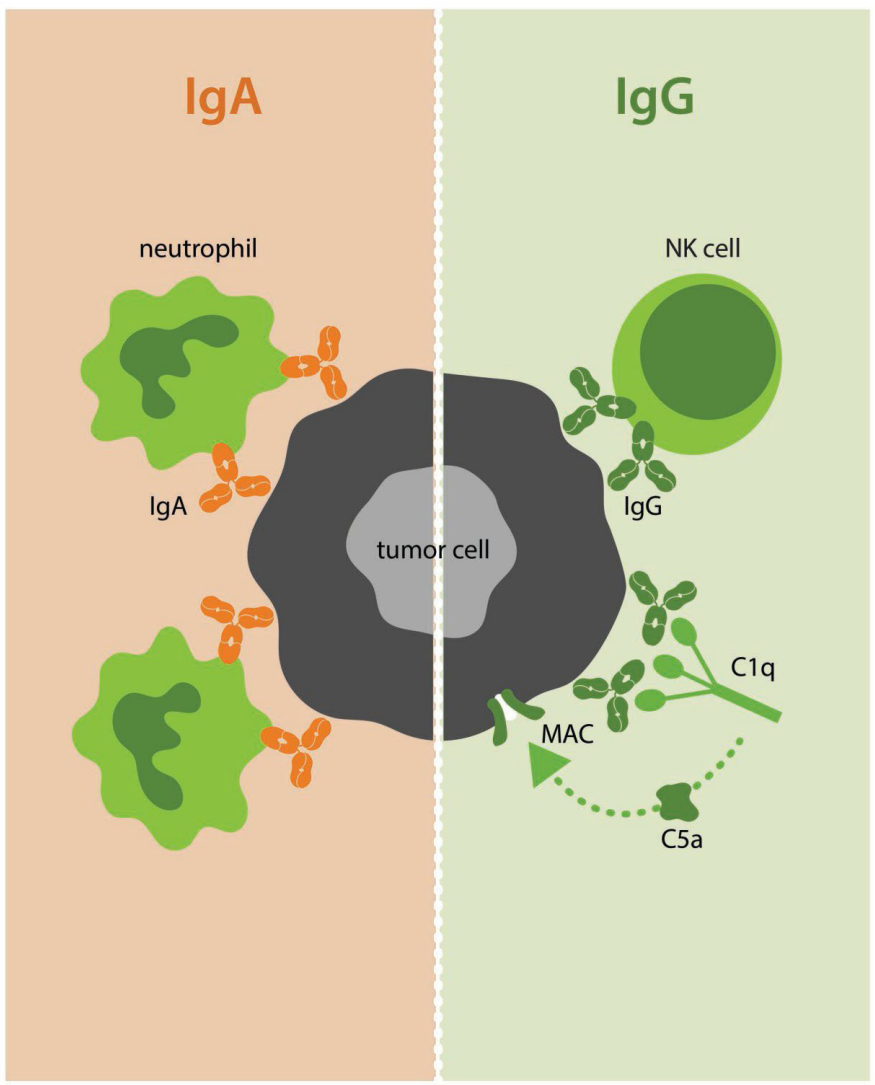

Adverse effects | peripheral nerves

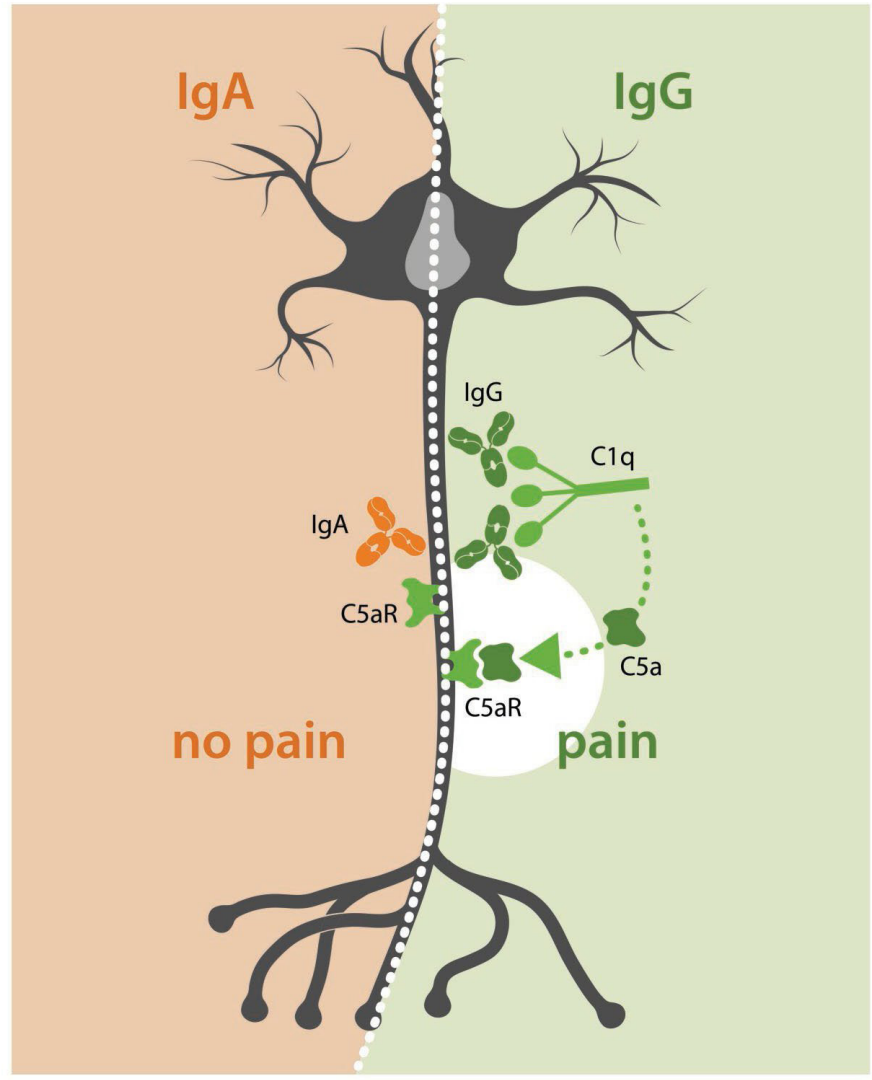

Figure 6 Summarizing figure. The left side of the figure shows the mechanism of action of $\lg A$ and $\lg G$ antibodies against GD2. IgA antibodies mediate killing of neuroblastoma cells with neutrophils as effector cells, while IgG antibodies do so via NK cells and CDC. On the right side of the figure, effects on GD2-expressing peripheral neurons are shown. Here, IgG activates the complement system, leading to pain. In contrast, IgA does not. CDC, complement-dependent cytotoxicity; NK, natural killer.

IgG will not lead to ADCC by PMN through this receptor. Therefore, Fc $\gamma$ RIIIb might act as a decoy receptor for IgG, reducing the ability of IgG to engage neutrophils in ADCC. ${ }^{25}$ In addition, IgA binds with a 1:2 stoichiometry to $\mathrm{Fc} \alpha \mathrm{R},{ }^{26}$ leading to greater activation of neutrophils. ${ }^{13}$ In our studies, we have used ch14.18 of the IgA1 isotype. In a clinical setting, use of IgA2 might be preferred due to the association of aberrantly glycosylated IgA1 antibodies with autoimmune disease. ${ }^{27}$

Besides neutrophils, monocytes and macrophages are potential effector cells in the treatment of neuroblastoma with IgA. Both monocytes and certain subsets of tissue resident macrophages express CD89. ${ }^{28-30}$ Due to the natural occurrence of tumor-associated macrophages within the neuroblastoma tumor microenvironment, they may represent a population of interest to activate against neuroblastoma. ${ }^{31}$ Indeed, IgA antibodies can induce similar ADCC with monocytes and antibody-dependent cell-mediated phagocytosis with macrophages against tumor cells as IgG, which warrants further investigation for use of these cells against neuroblastoma. ${ }^{1432} 33$

Next to an inherent vulnerability of neuroblastoma cells to neutrophil-mediated killing, the timing of the current treatment protocol also favors an approach where neutrophils are used as effector cells. Currently, patients with high-risk neuroblastoma are treated with a myeloablative regimen followed by autologous stem cell transplantation. ${ }^{2}$ Shortly thereafter, the immunotherapeutic protocol with IgG1 ch14.18 is started. Less than $25 \%$ of patients reached proper immune reconstitution for NK cells at the moment of immunotherapy, which might reduce NK cell-mediated killing against neuroblastoma. ${ }^{34}$ In contrast, neutrophils are among the first leukocyte subsets to be restored to physiological levels and are therefore a clinically important population to engage for tumor killing in this partially immune-compromised state $^{3435}$ Alternatively, the Children's oncology group is also conducting a trial (ANBL17P1) to assess dinutuximab upfront with chemotherapy which is based on a previous single-institution phase II trial that showed promising responses (NCT01576692).

At present, the preferred treatment schedule with ch14.18 treatment contains GM-CSF and IL-2. GM-CSF improves granulocyte and macrophage-mediated ADCC against neuroblastoma. ${ }^{36}$ In our studies, IgA mediated killing, was improved by the addition of GM-CSF. On the contrary, IL-2 did not improve IgA-mediated or IgGmediated killing by neutrophils, as expected. IL-2 was added to the clinical regimen after positive results were seen in adult patients with GD2-expressing melanoma and 
sarcoma after treatment with ch14.18 in combination with IL-2. ${ }^{37}$ A clinical trial which compared immunotherapy with and without IL-2 for treatment of neuroblastoma indicated that the addition of IL-2 did not have significant effects on EFS or overall survival and that early termination because of toxicity was significantly higher in the IL-2 arm. ${ }^{38}$ Recently, a phase-III clinical study indicated that addition of subcutaneous administration of IL-2 in combination with ch14.18 cells did not improve outcome in comparison to ch14.18 alone. ${ }^{39}$ Although IL-2 is of importance for the immune reconstitution of NK cells and lymphocytes, the necessity of IL-2 treatment for further studies with IgA should be reevaluated.

Improving the predictability of in vivo models is much desired, and patient-derived xenografts (PDXs) can offer models which mimic the molecular and phenotypical features of patients more closely. Although these PDXs offer tumors that are more similar to the clinical situation, the mice used for these studies are not. ${ }^{40}$ NODSCID-gamma mice are often used for these studies and lack a functional, T, B and NK cell compartment and the occurring macrophages and dendritic cells are defective. In addition, the complement system of these mice is also compromised, while neutrophils are still present and functional. Therefore, a comparison of IgA and IgG in these mice is not appropriate. This is the reason why we used syngeneic immune-competent mouse models, because the aforementioned effector cells and mechanisms are present.

Although EL4 cells do naturally express GD2 and are often used for anti-GD2 in vivo antibody models, they are not neuroblastoma cells. ${ }^{41-44}$ Alternatively, to the EL4 in vivo models, NXS2 murine neuroblastoma cells are another model to study therapeutic antibodies against neuroblastoma in vivo. ${ }^{45}$ Unfortunately, these cells are derived from the A/J mouse strain and an FcoRtransgenic mouse on that background does not exist, so this model could not be used for our experiments.

Neuropathic pain is a complex side effect caused after ch14.18 administration. To assess induction of pain in vivo we used the von Frey method as was described previously for ch14.18 induced pain. ${ }^{11}$ Others methods have been described to determine pain behavior in mice. ${ }^{46}$ Ideally, antibody-induced pain should be assessed by more than a single type of nociception assay. However, it remains unknown which methodology would be most relevant to quantify the pain mediated by ch14.18. This is an important question which requires further investigation.

In our pain studies, we dosed mice with five times the amount of IgA compared with IgG1 to adjust for the innate difference in half-life between these isotypes in mice. Although this complicates head-to-head in vivo comparisons, a similar neuronal exposure and serum concentration could be achieved. In humans, the in vivo half-life of IgA is approximately 1 week, which strikingly approximates that of ch14.18 in children with high-risk neuroblastoma. ${ }^{47}$ Therefore, we do not envision the half-life of IgA to limit its clinical efficacy. In contrast, the difference in half-life between IgG and IgA in mice is much bigger, due to strong hepatic clearance and an artificially high binding of human IgG to mouse FcRn. ${ }^{178}$ Several approaches have been undertaken to improve the half-life of IgA. ${ }^{49} 50$

In summary, our studies stimulate further investigations on the use of IgA against neuroblastoma. IgA offers both improved neutrophil activation and the benefit of overcoming pain in one single molecule. Our preclinical data suggests that IgA could be dosed higher than IgG without side effects. Therefore, IgA should be further explored as a next-generation therapeutic for neuroblastoma.

\section{Author affiliations}

${ }^{1}$ Center for Translational Immunology, UMC Utrecht, Utrecht, The Netherlands ${ }^{2}$ Department of Pediatric Hemato-oncology, Princess Maxima Center for Pediatric Oncology, Utrecht, The Netherlands

${ }^{3}$ Section for Stem Cell Transplantation and Immunotherapy, Department of Medicine II, Christian-Albrechts-University Kiel and University Medical Center SchleswigHolstein Campus Kiel, Kiel, Germany

Acknowledgements We would like to thank Eline van Diest for help with HPLC of antibodies.

Contributors ME conceptualized and designed the study, performed data acquisition, data interpretation and analysis and drafted/revised the manuscript. MS performed data acquisition, data interpretation and analysis and revised the manuscript. KK designed the study, performed data acquisition, data interpretation and analysis and drafted/revised the manuscript. HW performed data acquisition, data interpretation and analysis and revised the manuscript. MN performed data acquisition, data interpretation and analysis and drafted/revised the manuscript. MJ performed data acquisition, data interpretation and analysis and revised the manuscript. CC performed data acquisition, data interpretation and analysis and drafted/revised the manuscript. KB performed data interpretation and analysis and revised the manuscript. SN revised the manuscript. TV drafted/revised the manuscript. NE conceptualized and designed the study and drafted/revised the manuscript. JL conceptualized and designed the study, performed data interpretation and analysis, drafted/ revised the manuscript and is the guarantor of this manuscript.

Funding ME and MJ are both funded by The Dutch cancer association: Grant number 7650. TV is supported by the German Research Organization (DFG Va124/9-1) and by intramural funding from the CAU. MS, KK, MN are funded by Villa Joep (project 17 IgA and anti-GD2). SN is funded by Villa Joep and de vrienden van het UMC Utrecht.

Competing interests $\mathrm{JL}$ is co-founder of TigaTx and ME is employed by TigaTx.

Patient consent for publication Not applicable.

Ethics approval All animal experiments were performed in accordance with international guidelines and approved by the Dutch Central Authority for Scientific Procedures on Animals (CCD) and the local experimental animal welfare body (AVD115002016410 and AVD115002015323).

Provenance and peer review Not commissioned; externally peer reviewed.

Data availability statement Data are available upon reasonable request. All data relevant to the study are included in the article or uploaded as supplementary information. Data is not available in a public repository. Data can be requested by contacting the corresponding author.

Supplemental material This content has been supplied by the author(s). It has not been vetted by BMJ Publishing Group Limited (BMJ) and may not have been peer-reviewed. Any opinions or recommendations discussed are solely those of the author(s) and are not endorsed by BMJ. BMJ disclaims all liability and responsibility arising from any reliance placed on the content. Where the content includes any translated material, BMJ does not warrant the accuracy and reliability of the translations (including but not limited to local regulations, clinical guidelines, terminology, drug names and drug dosages), and is not responsible for any error and/or omissions arising from translation and adaptation or otherwise. 
Open access This is an open access article distributed in accordance with the Creative Commons Attribution Non Commercial (CC BY-NC 4.0) license, which permits others to distribute, remix, adapt, build upon this work non-commercially, and license their derivative works on different terms, provided the original work is properly cited, appropriate credit is given, any changes made indicated, and the use is non-commercial. See http://creativecommons.org/licenses/by-nc/4.0/

\section{ORCID iDs}

Mitchell Evers http://orcid.org/0000-0002-2940-5496

Thomas Valerius http://orcid.org/0000-0001-9181-8067

Jeanette Leusen http://orcid.org/0000-0003-4982-6914

\section{REFERENCES}

1 Maris JM. Recent advances in neuroblastoma. N Engl J Med 2010;362:2202-11.

2 Yu AL, Gilman AL, Ozkaynak MF, et al. Anti-GD2 antibody with GMCSF, interleukin-2, and isotretinoin for neuroblastoma. $N$ Engl J Med 2010;363:1324-34

3 Armideo E, Callahan C, Madonia L. Immunotherapy for high-risk neuroblastoma: management of side effects and complications. $J$ Adv Pract Oncol 2017;8:44-55.

4 Bertolizio G, Otis A, Tam K, et al. Multimodal analgesic plan for children undergoing chimeric 14.18 immunotherapy. J Pediatr Hematol Oncol 2021;43:e169-72.

5 Gilman AL, Ozkaynak MF, Matthay KK, et al. Phase I study of ch14.18 with granulocyte-macrophage colony-stimulating factor and interleukin-2 in children with neuroblastoma after autologous bone marrow transplantation or stem-cell rescue: a report from the Children's Oncology Group. J Clin Oncol 2009;27:85-91.

6 Bruchelt G, Handgretinger R, Fierlbeck G, et al. Lysis of neuroblastoma cells by the ADCC-reaction: granulocytes of patients with chronic granulomatous disease are more effective than those of healthy donors. Immunol Lett 1989;22:217-20.

7 Cheung IY, Hsu K, Cheung N-KV. Activation of peripheral-blood granulocytes is strongly correlated with patient outcome after immunotherapy with anti-GD2 monoclonal antibody and granulocytemacrophage colony-stimulating factor. J Clin Oncol 2012;30:426-32.

8 Mueller BM, Romerdahl CA, Gillies SD, et al. Enhancement of antibody-dependent cytotoxicity with a chimeric anti-GD2 antibody. $\mathrm{J}$ Immunol 1990;144:1382-6.

9 Xiao WH, Yu AL, Sorkin LS. Electrophysiological characteristics of primary afferent fibers after systemic administration of anti-GD2 ganglioside antibody. Pain 1997;69:145-51.

10 Navid F, Sondel PM, Barfield R, et al. Phase I trial of a novel anti-GD2 monoclonal antibody, Hu14.18K322A, designed to decrease toxicity in children with refractory or recurrent neuroblastoma. J Clin Oncol 2014;32:1445-52.

11 Sorkin LS, Otto M, Baldwin WM, et al. Anti-GD(2) with an FC point mutation reduces complement fixation and decreases antibodyinduced allodynia. Pain 2010;149:135-42.

12 de Sousa-Pereira P, Woof JM. IgA: structure, function, and developability. Antibodies 2019;8:57. doi:10.3390/antib8040057

13 Brandsma AM, Bondza S, Evers M, et al. Potent Fc receptor signaling by IgA leads to superior killing of cancer cells by neutrophils compared to IgG. Front Immunol 2019;10:704.

14 Brandsma AM, Ten Broeke T, Nederend M, et al. Simultaneous targeting of $\mathrm{Fc} \gamma \mathrm{Rs}$ and $\mathrm{Fc} \alpha \mathrm{RI}$ enhances tumor cell killing. Cancer Immunol Res 2015;3:1316-24.

15 Willemen HLDM, Kavelaars A, Prado J, et al. Identification of FAM173B as a protein methyltransferase promoting chronic pain. PLoS Biol 2018;16:e2003452.

16 Chaplan SR, Bach FW, Pogrel JW, et al. Quantitative assessment of tactile allodynia in the rat paw. J Neurosci Method 1994;53:55-63.

17 Boross $\mathrm{P}$, Lohse S, Nederend $\mathrm{M}$, et al. IgA EGFR antibodies mediate tumour killing in vivo. EMBO Mol Med 2013;5:1213-26.

18 van Egmond $\mathrm{M}$, van Vuuren $\mathrm{AJ}$, Morton $\mathrm{HC}$, et al. Human immunoglobulin A receptor (FcalphaRI, CD89) function in transgenic mice requires both FcR gamma chain and CR3 (CD11b/CD18). Blood 1999;93:4387-94.

19 Furman WL, Federico SM, McCarville MB, et al. A phase II trial of Hu14.18K322A in combination with induction chemotherapy in children with newly diagnosed high-risk neuroblastoma. Clin Cancer Res 2019;25:6320-8.

20 Li J, Stagg NJ, Johnston J, et al. Membrane-proximal epitope facilitates efficient $\mathrm{T}$ cell synapse formation by Anti-FcRH5/ CD3 and is a requirement for myeloma cell killing. Cancer Cell 2017;31:383-95.
21 Anghelescu DL, Goldberg JL, Faughnan LG, et al. Comparison of pain outcomes between two anti-GD2 antibodies in patients with neuroblastoma. Pediatr Blood Cancer 2015;62:224-8.

22 Terme M, Dorvillius M, Cochonneau D, et al. Chimeric antibody c.8B6 to O-acetyl-GD2 mediates the same efficient anti-neuroblastoma effects as therapeutic ch14.18 antibody to GD2 without antibody induced allodynia. PLoS One 2014;9:e87210.

23 Leusen JHW. IgA as therapeutic antibody. Mol Immunol 2015;68:35-9.

24 Unkeless JC, Shen Z, Lin CW, et al. Function of human Fc gamma RIIA and Fc gamma RIIIB. Semin Immunol 1995;7:37-44.

25 Derer S, Glorius P, Schlaeth M, et al. Increasing Fc $\gamma R$ Illa affinity of an FcyRIII-optimized anti-EGFR antibody restores neutrophil-mediated cytotoxicity. MAbs 2014;6:409-21.

26 Herr AB, Ballister ER, Bjorkman PJ. Insights into IgA-mediated immune responses from the crystal structures of human FcalphaRI and its complex with IgA1-Fc. Nature 2003;423:614-20.

27 Suzuki H, Yasutake J, Makita Y, et al. IgA nephropathy and IgA vasculitis with nephritis have a shared feature involving galactosedeficient IgA1-oriented pathogenesis. Kidney Int 2018:93:700-5.

28 Monteiro RC, Kubagawa H, Cooper MD. Cellular distribution, regulation, and biochemical nature of an Fc alpha receptor in humans. J Exp Med 1990;171:597-613.

29 van Egmond M, van Garderen E, van Spriel AB, et al. FcalphaRIpositive liver Kupffer cells: reappraisal of the function of immunoglobulin A in immunity. Nat Med 2000;6:680-5.

30 Sibille $Y$, Chatelain B, Staquet $P$, et al. IgA receptors on human alveolar macrophages. Monogr Allergy 1988;24:282-6.

31 Asgharzadeh S, Salo JA, Ji L, et al. Clinical significance of tumorassociated inflammatory cells in metastatic neuroblastoma. $\mathrm{J}$ Clin Oncol 2012;30:3525-32.

32 Borrok MJ, Luheshi NM, Beyaz N, et al. Enhancement of antibodydependent cell-mediated cytotoxicity by endowing IgG with FcalphaRI (CD89) binding. MAbs 2015;7:743-51

33 Lohse S, Brunke C, Derer S, et al. Characterization of a mutated IgA2 antibody of the $\mathrm{m}(1)$ allotype against the epidermal growth factor receptor for the recruitment of monocytes and macrophages. J Biol Chem 2012;287:25139-50.

34 Nassin ML, Nicolaou E, Gurbuxani S, et al. Immune reconstitution following autologous stem cell transplantation in patients with highrisk neuroblastoma at the time of immunotherapy. Biol Blood Marrow Transplant 2018;24:452-9.

35 Szanto CL, Cornel AM, Tamminga SM, et al. Immune monitoring during therapy reveals activitory and regulatory immune responses in high-risk neuroblastoma. Cancers 2021;13:1. doi:10.3390/ cancers13092096

36 Batova A, Kamps A, Gillies SD, et al. The Ch14.18-GM-CSF fusion protein is effective at mediating antibody-dependent cellular cytotoxicity and complement-dependent cytotoxicity in vitro. Clin Cancer Res 1999;5:4259-63.

37 Choi BS, Sondel PM, Hank JA, et al. Phase I trial of combined treatment with ch14.18 and R24 monoclonal antibodies and interleukin-2 for patients with melanoma or sarcoma. Cancer Immunol Immunother 2006;55:761-74.

38 Ladenstein R, Weixler S, Baykan B, et al. Ch14.18 antibody produced in $\mathrm{CHO}$ cells in relapsed or refractory stage 4 neuroblastoma patients: a SIOPEN phase 1 study. MAbs 2013;5:801-9.

39 Ladenstein R, Pötschger U, Valteau-Couanet D, et al. Interleukin 2 with anti-GD2 antibody ch14.18/CHO (dinutuximab beta) in patients with high-risk neuroblastoma (HR-NBL1/SIOPEN): a multicentre, randomised, phase 3 trial. Lancet Oncol 2018;19:1617-29

40 Braekeveldt N, Bexell D. Patient-derived xenografts as preclinical neuroblastoma models. Cell Tissue Res 2018;372:233-43.

41 Vincent M, Bessard A, Cochonneau D, et al. Tumor targeting of the IL-15 superagonist RLI by an anti-GD2 antibody strongly enhances its antitumor potency. Int J Cancer 2013;133:757-65.

42 Imai M, Landen C, Ohta R, et al. Complement-mediated mechanisms in anti-GD2 monoclonal antibody therapy of murine metastatic cancer. Cancer Res 2005;65:10562-8.

$43 \mathrm{Kim}$ S-K, Wu X, Ragupathi G, et al. Impact of minimal tumor burden on antibody response to vaccination. Cancer Immunol Immunother 2011;60:621-7.

44 Alvarez-Rueda N, Desselle A, Cochonneau D, et al. A monoclonal antibody to O-acetyl-GD2 ganglioside and not to GD2 shows potent anti-tumor activity without peripheral nervous system crossreactivity. PLoS One 2011;6:e25220.

45 Neal ZC, Imboden M, Rakhmilevich AL, et al. NXS2 murine neuroblastomas express increased levels of $\mathrm{MHC}$ class I antigens upon recurrence following NK-dependent immunotherapy. Cancer Immunol Immunother 2004;53:41-52. 
46 Turner PV, Pang DS, Lofgren JL. A review of pain assessment methods in laboratory rodents. Comp Med 2019;69:451-67.

47 Desai AV, Fox E, Smith LM, et al. Pharmacokinetics of the chimeric anti-GD2 antibody, ch14.18, in children with high-risk neuroblastoma. Cancer Chemother Pharmacol 2014;74:1047-55.

48 Nilsen J, Bern M, Sand KMK, et al. Human and mouse albumin bind their respective neonatal Fc receptors differently. Sci Rep 2018;8:14648
49 Mester S, Evers M, Meyer S, et al. Extended plasma half-life of albumin-binding domain fused human IgA upon $\mathrm{pH}$-dependent albumin engagement of human $\mathrm{FcRn}$ in vitro and in vivo. MAbs 2021;13:1893888.

50 van Tetering G, Evers M, Chan C, et al. Fc engineering strategies to advance IgA antibodies as therapeutic agents. Antibodies 2020;9:70. doi:10.3390/antib9040070 